\title{
CAUSES OF MENORRHAGIA IN FEMALES BETWEEN 21-50 YEARS OF AGE ATTENDING THE OUT PATIENT DEPARTMENT OF NASEER TEACHING HOSPITAL
}

\author{
Anjum Ara ${ }^{1}$, Naheed Rahim ${ }^{1}$ \\ 1. Naseer Teaching Hospital
}

\begin{abstract}
OBJECTIVES:

To determine the causes of menorrhagia

\section{MATERIAL AND METHODS:}

This case series study was conducted in the department of obstetrics and Gyneacology Naseer Teaching Hospital Peshawar over a period of one year from June 2006 to May 2007. Eighty patients with menorrhagia were studied between ages of 21-50 years. All patients were thoroughly investigated for the causes of menorrhagia. All the patients having menstrual blood loss of more than eight days or history of passage of clots or having hemoglobin less than $\mathrm{log} / \mathrm{dl}$ were included in the study and patients having pubertal menorrhagia, less than 20 years of age or postmenopausal patients, on hormonal replacement therapy were excluded from the study.
\end{abstract}

\section{RESULTS:}

Out of total eighty patients, the commonest age group was above 40 years i.e.63.75\% ( $n=51)$. The most common cause of menorrhagia was fibroid uterus in $47.5 \%$ ( $n=38)$ cases followed by adenomyosis in $25 \%$ $(n=20)$ cases, endometrial polyp in $7.5 \%(n=6)$ cases, endometrial hyperplasia in $6.25 \%(n=5)$ cases, injectable progestogens in $6.25 \%(n=5)$ cases, intrauterine contraceptive device in $5 \%(n=4)$ cases. 30 patients (37.5\%) were multipara, $25(31.25 \%)$ were grand multipara and $25(31.25 \%)$ were great grand multipara.All of them were anemic. Severe anemia (hemoglobin < $6 \mathrm{gm} \%)$ was found in one case $(1.25 \%)$, moderate anemia (hemoglobin 6-8 gm\%) in 45 cases (56.25\%) and mild anemia (hemoglobin 8-10 gm\%) in 34 cases (42.75\%). Abdominal ultrasound alone was done in 63 cases $(70.75 \%)$, and transvaginal ultrasound in 17 patients (21.25\%). The diagnosis of fibroid uterus, endometrial polyp and endometrial hyperplasia was confirmed on ultrasound.

\section{CONCLUSION:}

In my study fibroid uterus (47.5\%), adenomyosis (25\%), endometrial polyp (7.5\%) and endometrial hyperplasia (6.25\%) were the common causes in patients presenting with menorrhagia to Naseer Teaching Hospital causing disruption and psychological problem for females.

\section{KEYWORDS:}

Type your text Menorrhagia, Fibroid uterus, endometrial polyp

\section{INTRODUCTION}

Menorrhagia is a grave problem of women due to lack of awareness and negligence. It can cause Disruption and psycological problems for many women. The purpose of my study was

Correspondence: Dr. Anjum Ara

Naseer Teaching Hospital

Contact: 0300-5856180 Email: ajnumara456@yahoo.com https://doi.org/10.37762/igmds.2-1.56 to find out the leading causes of menorrhagia in females and its effects on their health. Menorrhagia is defined as excessive cyclic uterine bleeding that occurs at regular intervals over several cycles, or prolonged bleeding that lasts for more than seven days ${ }^{1}$. Average menstrual blood loss is between 30 and $40 \mathrm{ml}^{\text {per cycle }}{ }^{2}$. An early population based study concluded that the upper limit of normal menstrual blood loss was between 60 and $80 \mathrm{ml}$, with upper limit subsequently adopted as the classic definition of 
menorrhagia ${ }^{3,4}$. Menorrhagia is one of the most common complaints in otherwise healthy women ${ }^{5}$.One in three women experienced the problem at some stage in their lives ${ }^{7} .7300$ hysterectomies are performed annually in UK, of which $35-64 \%$ are for menorrhagia. In up to $50 \%$ of these cases no pathology is found on histological examination of the uterus.Causes of menorrhagia may be local, systemic or dysfunctional. Established risk factors for menorrhagia include age ${ }^{8}$. leiomyomata ${ }^{9}$ and endometrial polyp ${ }^{10}$. Parity, body mass index and smoking are not risk factors 8. For some women, a cause of menorrhagia is not identified. Abnormalities of platelet function, such as Von willebrands disease, appear to be more prevalent in women with menorrhagia than in the general population ${ }^{1,11}$. There are no data suggesting that lower quality of life occurs more commonly in women with menorrhagia and Von willebrand's disease than in those with menorrhagia alone ${ }^{12}$. The most common anatomic causes in menstrual disorders in premenopausal women are uterine polyps and submucous Fibroid ${ }^{13}$, although disturbance of prostaglandin synthesis or metabolism or local coagulation mechanism may be involved. Other local causes include leiomyoma, adenomyosis, endometriosis, endometrial polyps, intrauterine contraceptive devices, endometrial hyperplasia,endometrial adenocarcinoma, polycystic ovarian disease congenital anomalies of uterus and sometime myometrial hypertrophy and uterine vascular malformation $12,13,14,15,16,18$. In rare cases menorrhagia can occur as a result of systemic disease which results in hepatic and renal impairment. Both hypo and hyperthyroidism can also cause heavy menstruation 17. In most of the cases no cause can be found. In a retrospective study of 117 menorrhagia patients by Syeda Batool Mazher it was found that in more than half of the patients with menorrhagia, no obvious abnormality was detected on examination and routine investigations ${ }^{19}$.

A Full blood count is useful to determine hemoglobin level and can be used to monitor treatment with haematinics ${ }^{20}$.An ultrasound scan of pelvis and abdomen is a useful tool in diagnosis and for describing masses suspected or actually found on physical examination especially in obese women where examination can be suboptimal ${ }^{20}$.An endometrial biopsy should be taken if a woman is over 40 or under 40 with particular risk like tamoxifen use, unopposed estrogen or obesity ${ }^{20}$.

\section{METHODOLOGY}

This case series study was conducted in Gynea unit of Naseer Teaching Hospital Peshawar over a period of one year form June 2006 to May 2007. All the patients were outdoor patients. Eighty patients with menorrhagia between 21-50 years of age were studied. Pre questioning was done in $10 \%$ of cases to make necessary changes in my questionare and final questionare was made. The purpose and benefits of the study were explained to all patients and they were assured that study is done purely for data publication and research purpose. Moreover they were also assured tha their confidentiality will be maintained. Detailed questions including age, socioeconomic status, parity, amount, duration and pattern of bleeding, number of sanitary pads soaked, any associated gynecological problem like dysmenorrhea, infertility, symptoms suggestive of myxedema or bleeding disorder, hormonal treatment or history of intrauterine contraceptive device were recorded on a performa. Detailed abdominal and pelvic examination was performed and patient investigated accordingly. All the patients having menstrual blood loss of more than eight days or history of passage of clots or having hemaoglobin less than 10 gram per deciliter were included in the study and patients having puberty menorrhagia, less than 20 years of age, postmenopausal patients and patients on hormone replacement therapy were excluded.

\section{RESULT}

Over a period of one year, 80 cases of menorrhagia were seen. The common age group was above 40 years $(63.75 \%)$. Twenty nine $(36.25 \%)$ cases were in the age range between $21-40$ 
years. Considering parity 30 patients had 1-5 parity, 25 had parity between 6-8, 25 patients had more than 8 parity (table 1). Regarding the casue of menorrhagia $38(47.5 \%)$ patients had fibroid uterus while $20(25 \%)$ had adenomyosis. Endometrial polyp was found in (7.5\%) (table 3).All of them were anemic at the time of presentation. (Table 2)

Table: 01 Age And Parity Wise Distribution

Of Sample $n=80$

\begin{tabular}{|c|c|c|c|}
\hline S. No & Age Range & Frequency & Percentage \\
\hline 1 & $21-40$ & 29 & $36.25 \%$ \\
\hline 2 & $>40$ years & 51 & $63.75 \%$ \\
\hline S. No & Parity & Frequency & Percentage \\
\hline 1 & $1-5$ & 30 & $37.5 \%$ \\
\hline 2 & $6-8$ & 25 & $31-25 \%$ \\
\hline 3 & More than 8 & 25 & $31-25 \%$ \\
\hline
\end{tabular}

Table: 02 Investigations Of Sample $n=80$

\begin{tabular}{|c|l|c|c|}
\hline S. No & \multicolumn{1}{|c|}{ HB } & Frequency & Percentage \\
\hline \multirow{3}{*}{1} & $<6 \mathrm{gm} \%$ & 1 & $1.25 \%$ \\
& $6-8 \mathrm{gm} \%$ & 45 & $56.25 \%$ \\
& $>8-<10 \mathrm{gm} \%$ & 34 & $42.75 \%$ \\
\hline \multirow{3}{*}{2} & Ultrasound: & & \\
& Transabdominal & 63 & $70.75 \%$ \\
& Transvaginal & 17 & 21.25 \\
\hline
\end{tabular}

Table: 03 Causes of Menorrhagia in Sample $n=80$

\begin{tabular}{|c|c|c|c|}
\hline S.No & Causes & $\begin{array}{c}\text { Frequency } \\
(\mathbf{n = 8 0})\end{array}$ & Percentage \\
\hline 1 & Fibroid uterus & 38 & $47.5 \%$ \\
\hline 2 & Adenomyosis & 20 & $25 \%$ \\
\hline 3 & Endometrial polyp & 6 & $7.5 \%$ \\
\hline 4 & Endometrial hyperplasia & 5 & $6.25 \%$ \\
\hline 5 & Endometriosis & 1 & 1.25 \\
\hline 6 & Ch. Endometritis & 1 & $1.25 \%$ \\
\hline 7 & IUCD induced & 4 & $5 \%$ \\
\hline 8 & Injectable Progestogens & 5 & $6.25 \%$ \\
\hline
\end{tabular}

\section{DISCUSSION}

The causes of menorrhagia may often be recognized on careful history and examination alone, although the majority requires more thorough evaluation. Causes may be local, systemic and dysfunctional. In our study all patients with menorrhagia had some cause on examination and routine investigation which is against the result of a retrospective study of 117 menorrhagia patients by Mazhar ${ }^{23}$ where in more than half of the cases no cause was found. In our study of 80 patients with menorrhagia the most common cause was leiomyoma which was commonest organic lesion of the uterus and was found in $47.5 \%$ of cases. This is comparable with the prospective study of 
121 patients with menorrhagia by Shagufta Shaheen ${ }^{21}$ who reported it to be $47.10 \%$ Adenomyosis was found in approximately $20 \%$ of removed uterus and probably is of more clinical significance than is generally recognized. In a study adenomyosis was found to be diagnosed correctly before surgery in $10 \%$ of cases ${ }^{22}$. In our study it was found in $25 \%$ of removed uteri (on histopathology) while in study by Shagufta Shaheen it was found in $30.05 \%{ }^{21}$.

Chronic endometritis has been known to follow pregnancy or abortion. It may be a result of intrauterine contraceptive device or accompanied by mucopurulent cervicitis and pelvic inflamatory disease $^{24}$. In a study conducted by Goldsten, 26(17\%) women with menorrhagia had isolated endometritis ${ }^{25}$. While in my study it was seen in $1.25 \%$ cases. Chronic endometriosis was found in $1.25 \%$ cases which is compared to Mackenzie where its incidence was $0.8 \%{ }^{23}$.

Endometerial hyperplasia can be caused by exposure of endometrium to continuous estrogen unopposed by progesterone. The diagnosis of endometrial hyperplasia should be suspected in women with prolonged, frequent or irregular uterine bleeding. In particular abnormal uterine bleeding in perimenopausal women is the most common symptom of endometrial neoplasia, although such bleeding is usually $80 \%$ due to a benign condition ${ }^{25}$. In my study the incidence of endometrial hyperplasia was $6.25 \%$ compared to study conducted by Fayaz S and Luqman where the incidences are $4.68 \%$ and $4 \%$ respectively ${ }^{26,27}$.

\section{CONCLUSION}

Fibroid uterus and Adenomyosis are the most common causes of menorrhagia found mostly in multigravidas causing anemia leading to disruption and psychological problems for many women.

\section{RECOMMENDATIONS}

Increased awareness of the problem and precise diagnosis using transvaginal ultrasound, endometrial sampling is required for the detection of the cause which will allow more precise treatment of the individual case.

\section{REFERENCE}

1. ACOG committee on Practice Bulletins Gynecology, ACOG Practice bulletin, management of anovulatory bleeding. Int J Gynaecol obstet. 2001; 72:263-71

2. Lyer V, Farquhar C, Jepson R. oral contraceptive pills for heavy menstrual bleeding Cochrane Data base syst. Rev.2000; (2): CD 000154.

3. Hall berg L, Hogdahl AM, Nilsson L, Rybo G. Menstrual blood loss-a population study. Variation at different ages and attempts, to define normality. Acta obstet Gynecol scand 1966;45:320-51

4. Warner PE, crotchety H, Lumsden MA, Campbell- Brown M. Douglas A, Murray GD. Menorrhagia is the $80 \mathrm{ml}$ blood loss criterion useful in management of complaint of menorrhagia. Am J obstet Gynecol. 2004; 190:1224-9.

5. Michael J, Gynnon O, Donovon. Update on endometrial ablation recent advances obstetrics and Gynaecology vol 23, 2005;159-68.

6. Mr. A. Meenakshi, Dr Metilda Bhuvaneshwari International Journal of scientific and Research publications, volume3, june 2013 2250-3153. 
7. Invine GA, Cemeron DR medical management of menorrhagia in pace review and answer, London, Royal College of obstetricians and Gynaecologists press; 1997:35-8.

8. Janssen CA, Scholten PC, Heintz AP, Menorrhagia a search for epidemiological risk markers Matuntas 1997; 28: 19-25.

9. Wegieka G, Baird DD, Hertz- picciottor I, Harlaw SD, SteegeJF, Hall Mc, etal Self- reported heavy bleeding associated with uterine leiomyomata obstet leiomyomata Obstet. Gynecol 2003, 10,:431-7.

10. Dewaay Dj, Syoop CH, Nygaard IE, Davis WA, Van Voorhis B. Natural History of uterine polyps and leiomyomata Obstet. Gynaecol 2002; 100: 3-7.

11. Phillp CS. Faiz A. Dowling N, Dilly A, Michael LA, Ayers C, etal Age and prevalence of bleeding disorders in women with menorrhagia Obstet Gynecol 2005: 61-6

12. James A, Matcher DB, Myers ER. Testing of von willebrand disease in women with menorrhagia: a system review obstet Gynecol 2004;104: 381-8

13. Dijkuizen FP, mal Bub Bongers MY, Brolmann HA, Heintz AP cost effectiveness of transvaginal sonography and saline infused sonography in the evaluation of menoorhagia Int .J Gyencol Obstet 2003, 83: 45-52.

14. Hutchins Uterine fibroids Diagnosis and indications for treatment Obstet Gynecol clin North Amm 1995;22 (4): 659-65.

15. Van Eijkkeren. Menorrhagia ;current drug treatment concepts .Drugs 1992;43-201-09.

16. Shaws RW. Treating the patient with menorrhagia Br. J. obstet gynaecol 1994; 101: 1-12

17. A huja, Kriplani. Von willebrand disease: a rare cause of puberty menorrhagia. Aust NZ obstet Gynaecol 1995;35(3): 337-8.

18. Manolitasas, uterine arteriovenous malformation :a rare cause of uterine haemorrhage Aust NZ obstet Gynaecol 1994; 334(2) 197-9

19. Mazhar SB. Transcervical endometrial resection for menorrhagia: A review of 117 consecutive cases. $J$ coll Physician surg Pak 1995; 5 (2) 5-7

20. Johnstone shabaya Misheso (2012) Menorrhagia and the Levonorgestril intrauterine system hysterectomy Dr. Ayman Al-Hendy ( Ea), ISBN: 978-953-51-0434-6

21. Shagufta Shaheen, Shahnaz Akhter, Naeema utman, causes of menorrhaiga and its pathological diagnosis by dilatation and curettage. JPM1 2005 vol 19 No.1: 62-66.

22. Goldrath and Husain. The hysterosopic management of endometrial leiomyomatosis $J$ Am Assoc Gynecol Laparose 1997; 4 (2) 263-7.

23. Mary E, Rimiza MD. Dysfunctional uterine bleeding. Pediatr Review 2002 ; 23 :227-33.

24. Cote I, Jacobs $P$, Cumming DC. Use of health services associated with increased menstrual loss in United States. AmJ Obstet Gynaecol 2003 ; 188:343-8. 
25. Goldrrath M.office hysteroscopy and sanction curettage in the evaluation of abnormal uterine bleeding. Cameron IT, Fraser IS, Smith SIC. Clinical disorders of the endometrium and menstrual cycle. Oxford University Press ; 1998.P 148-54.

26. Mackenzie MD, Johnson NP. Menstrual cycle characteristics and risk of endometriosis. Am J Obsetet Gynecol 2001;180: 1040-9.

27. Steiner RA. Fink D. Abnormal menstrual bleeding. Schweiz Rundsch Med prax 2002 Nov. 13 ; $91: 1967-$ 74.

28. Goldstein SR Menorrhagia and abnormal uterine bleeding before the menopause Best Pract Res Clin obstet Gynaecol 2004 ; 18(1):59-69.

29. Fayyaz S, Majeed SS. Audit of gynaecological hysterectomies. J Post grad. Med Inst 2001, 15(2) : 20812.

30. Luqman m, Bukhari L. Abnormal excessive uterine haemorrhage : a histopathological study Pak J Pathol 1998; $9: 20-3$.

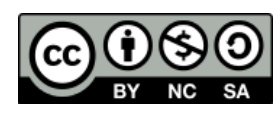

LICENSE: JGMDS publishes its articles under a Creative Commons Attribution Non-Commercial Share-Alike license (CC-BY-NC-SA 4.0). COPYRIGHTS: Authors retain the rights without any restrictions to freely download, print, share and disseminate the article for any lawful purpose. It includes scholarly networks such as Research Gate, Google Scholar, LinkedIn, Academia.edu, Twitter, and other academic or professional networking sites. 